\title{
ВНЕШНЕЕ УПРАВ/ЕНИЕ
}

\author{
С.С. Хизриева
}

\section{ОСОБЕННОСТИ ФОРМИРОВАНИЯ ИМИДЖА ФЕДЕРАТИВНОЙ РЕСПУБЛИКИ БРАЗИЛИЯ В РОССИЙСКОЙ ФЕДЕРАЦИИ}

\begin{abstract}
Аннотация. В начале двадиать первого века важной особенностью внешней политики Федеративной республики Бразилия стало формирование нового позитивного имиджа страны, направленного на значительное снижение влияния США на политику Бразилии. В определении ориентиров внешней политики Бразилии важньм бактором является отношения с Россией. Бразилия стремится выдвинуть на первый план межрегиональную интеграцию как важную особенность развития стратегии страны, а также международное стратегическое партнерство, тем самым добивается качественно нового статуса на политической арене. В исследовании использованы системный, структурно-функииональный, культурно-ицвилизационныци, сравнительно-исторический и сравнительно-политический подходь, методы индукиии, дедукиии, наблюдения, анализа, синтеза, аналогии. В результате автор приходит к выводу, что в начале ХХІ века, происходит укрепление позиций Бразилии в мире, что во многом повлекло за собой изменение информачии СМИ о ней. Начиная с этого периода страна, пересматривает свои экономические (отказ от неолиберализма) и политические направления (левый nоворот).
\end{abstract}

Ключевые слова: управление, тренды, Бразилия, США, Россия, Лула да Силва, БРИКС, имидж, национальная стратегия, брендинг

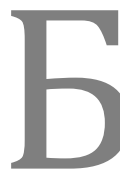

разилия ищет новые пути сотрудничества среди развивающихся стран, при этом, исключая тесное сотрудничество с США. С приходом Лулы да Силвы на пост президента Бразилии начинается более тесное сотрудничество с Россией, тем самым появляются новые возможности для улучшения ее имиджа в России, а также России в Бразилии. Бразилия выступает с инициативой объединения с Россией, Индией и Китаем. Данную группу стран эксперты инвестиционного банка назвали БРИКС, эта аббревиатура вошла в научный обиход и прижилась в СМИ. По подсчетам экспертов эти страны к 2050 г. будут занимать лидирующее положение в мировой экономике и политике. ВВП Бразилии к указанному сроку будет составлять 6,07 трлн. долларов, Россия - 5,58, Индия - 27,80, Китай - 44,451, тем самым в совокупности превзойти суммарный объем ВВП “большой шестерки”. В критерии объединения

\footnotetext{
${ }^{1}$ Dreaming with BRICs. The Path to 2050. Global economics paper N 99 [Электронный ресурc]. URL: http.//www.gs.com/ inglish/research/reports/report6.html (17.03.2011)
}

данных стран выступает: территориальный признак - страны-гиганты, многочисленное население, значительной экономикой и ресурсами. Обратившись к официально опубликованному на сайте МИДа Бразилии документу Balanзo de Polntica Externa 2003/2010² можно сделать вывод, что правительство Бразилии попыталось расширить и укрепить отношения со странами, проблемы и перспективы которых относительно существующего международного положения расценены были как сходящиеся. Стремление к построению многополярного мира объединяет эти страны, цель которого противостояние гегемонии США.

Образ России в Бразилии размыт и неопределен по большей части в силу недостаточной информации о ней, а также по причине пассивности российских официальных лиц и общественных структур в деле распространения таковой. По мнению

\footnotetext{
${ }^{2}$ Balanзo de Polntica Externa 2003/2010. [Электронный реcypc]. URL: http://www.itamaraty.gov.br/temas/balanco-de-politicaexterna-2003-2010 (29.04.2011)
} 


\section{Внешнее управление}

известного российского ученого Б.Ф. Мартынова: «бразильцы неудовлетворенны в целом достаточно низкой приоритетностью Бразилии и стран Латинской Америки для России» э это связанно с низкой интенсивностью связей между странами. Также обстоят дела с подачей информации в Бразилии о России. Так массив позитивной информации о России неожиданно появляется летом 2006г. в связи с проведением саммита «Большой восьмерки» в Санкт- Петербурге, был напрямую связан с приглашением на саммит Лулы. Широкое освящение этого мероприятия в бразильской печати, связанно было с надеждой Бразилии войти в неформальный «клуб избранных», и кроме того, вынести в центр его повестки дня энергетическую проблему, к которой эта страна начала на тот момент проявлять возрастающий интерес, все это как бы заранее предопределило повышенное внимание бразильских СМИ к России и позитивные отклики на ее политику.

Бразильское информационное агентство Estado de Sao Paulo сообщило своим читателям о том, что «Голос России вновь твердо зазвучал на международной арене» и что «Владимир Великий вернул русским национальную гордость» ${ }^{4}$. Комментируя итоги саммита, газета отметила стремление России проводить независимый курс в сфере внешней и энергетической политики, «отвергая навязываемые ей стандарты поведения». Globo в редакционной статье «Звездный час Путина» писала что «итоги саммита свидетельствуют о триумфе российского руководства» и что «Россия сделала огромный шаг вперед и теперь русские могут вновь испытывать гордость за свою страну и то место, которое она занимает в мире» 5 . Аналогичный всплеск позитивного интереса к России можно было констатировать в Бразильской прессе после решения МОК о проведении зимних Олимпийских игр 2014года в Сочи.

При анализе информации бразильских СМИ о России становится ясно, что «позитив» возникает всегда, когда речь идет о совпадении позиций по тем или иным актуальным вопросам мировой экономики и политики (как в случае прямой

\footnotetext{
${ }^{3}$ Мартынов Б.Ф., Константинова Н.С., Проценко А.Е. Имидж России и его восприятие в Бразилии. - М.: ИЛА PAH, 2009.- C.80.

${ }^{4}$ O Estado de Sao Paulo, 16.07. 2006

${ }^{5} \mathrm{O}$ Globo, 18.07.2006
}

поддержке России тех или иных бразильских инициатив).

Первый саммит БРИКС прошел 16 июня в Екатеринбурге. Встреча проходила на высшем уровне в ней приняли участие лидеры России, Бразилии, Китая, Индии. По итогам первого саммита главы государств БРИК приняли Совместное заявление, а также Документ по глобальной продовольственной безопасности. Так если обратиться к официально опубликованному Совместному заявлению лидеров стран БРИК ${ }^{6}$, то в нем:

1) признается центральная роль, «которую играют саммиты «Группы двадцати» в противодействии финансовому кризису. Они укрепили сотрудничество, координацию политики и политический диалог, касающиеся международных экономических и финансовых вопросов»;

2) выражается «приверженность продвижению реформы международных финансовых институтов с тем, чтобы она отражала изменения в мировой экономике. Страны с переходной и развивающейся экономикой должны иметь больший голос и представительство в международных финансовых институтах, а их главы и сотрудники руководящего звена должны назначаться через открытую, прозрачную и основанную на заслугах систему отбора»;

3) призыв к международному сообществу «сохранить стабильность системы многосторонней торговли, сдерживать торговый протекционизм и добиваться всеобъемлющих и сбалансированных результатов Дохийского раунда развития ВТО»

4) «за укрепление координации и сотрудничества государств в энергетической области, в том числе между производителями и потребителями энергии и государствами транзита, в усилиях по снижению неопределенности и обеспечению стабильности и устойчивости. Мы поддерживаем диверсификацию энергетических ресурсов и предложения энергоносителей, включая возобновляемую энергию, обеспечение безопасности маршрутов транзита энергоносителей, создание новой энергетической инфраструктуры и направление новых инвестиций в энергетику» ${ }^{7}$

\footnotetext{
${ }^{6}$ Совместное заявление лидеров стран БРИК 16 июня 2009 года// Президент России [Электронный ресурс]. URL: http://news.kremlin.ru/ref_notes/209 (17.04.2011)

${ }^{7}$ Совместное заявление лидеров стран БРИК 16 июня 2009 года// Президент России [Электронный ресурс]. URL: http://news.kremlin.ru/ref_notes/209(17.04.2011)
} 


\section{Тренды и управление 2(6) 2014}

На основе вышеперечисленных выдержек из Совместного заявления лидеров стран БРИКС, можно сделать вывод о том, что данное объединение основано не только на обоюдных экономических интересах (пункты 1,2,3) , а так же на схожих проблемах. В частности в пункте 4-ом под производителям энергии в данном документе подразумеваются - Россия и Бразилия (обе страны ресурсо-самодостаточные), под потребителями энергии подразумеваются, прежде всего: Китай, Индия. Данные страны обеспокоены обеспечением «безопасности маршрутов транзита энергоносителей» в частности нефти и газа, угля. Прецедентом были серии скандалов России с Украиной, начиная с 2003г. по поводу незаконной перекачки нефти транзитом поступающей в Европу на территории Украины, а так же скандал с Белоруссией. Данные скандалы существенно отразились на имидже России и деловой репутации, что не могли не учесть страны группы БРИК. Принятие данного пункта совместно с Россией неформально Бразилия, Китай, Индия оказывают поддержку России в противовес обвинениям с Европы и США в ненадежности России как поставщика нефти и газа.

8 октября 2010г. подписан в рамках VI Бразильско-Российской Межправительственной комиссии по сотрудничеству Меморандум о взаимопонимании между Министерствами науки и технологий Республики Бразилия и Министерством образования и науки Российской Федерации о сотрудничестве в области нанотехнологий. На основе данного документа можно говорить: 1) о развитии сотрудничества в области нанотехнологий основанных на принципе взаимной выгоды; 2) о развитие сотрудничества: в фундаментальных исследованиях нанообъектов, изучении и разработке наноматериалов, развитие нанотехнологий, а также его производства, подготовка кадров для наноиндустрии. В результате данного меморандума создается Координационный комитет.

Для оценки эффективности внешней политики президента Бразилии Луиса Инансиу Лула да Силва предполагается необходимым анализ СМИ. Наиболее приемлемым для достижения данной цели представляется метод контент - анализа. Контент - анализ - это анализ содержания, обработка неструктурированного текста на частотность слов, стилевых оборотов, близость слов. Для контент - анализа необходимо определить основные понятия исследования:
Объект - президент Лула да Силва

Предмет - политика Лулы да Силва

Проблема - восприятие Лулы в России

Цель - выявить эффективность коммуникационной политики.

Задача - анализ СМИ России для выявления позитивных, негативных и нейтральных оттенков публикаций.

Категория анализа - тип публикации: позитивный, негативный и нейтральный.

Единица анализа - часть текста.

«Основываясь на заданной категории анализа уместно ввести такой параметр, как индекс информационного благоприятствия, на основе которого и будет строится дальнейшее исследование.

Индекс объекта в отдельном сообщении рассчитывается на основе трех основных компонентов:

- оценки характера упоминания объекта в сообщении - позитивная, негативная, нейтральная;

- показателя «яркости», который складывается из роли объекта в сообщении - главной, второстепенной, эпизодической, наличия прямой или косвенной речи и конфликтности ситуации;

\section{- $\quad$ влиятельности СМИ}

Для оценки качественной составляющей информационного поля объекта за определенный период времени используется «Валовой индекс» (в.и.) - сумма индексов объекта во всех выбранных сообщениях» ${ }^{8}$.

Числовое значение индекса для объекта в каждом сообщении может колебаться от -10 до +10. Например, обьект т.е. персона, может получить максимальный индекс, если статья оне будет опубликована в влиятельном СМИ, а автор статьи осветит данную персону в исключительно положительном ключе. В данном случае ниже будут приведены данные по всем трем обозначенным критериям, каждый будет оценен в соответствии с заданной шкалой.

Для оценки положения в информационном поле России были взяты три ключевых издания данной страны, а именно: РБК daily, Коммерсантъ, Эксперт, Аргументы и факты.

\footnotetext{
${ }^{8}$ Хриптулова О.И. Коммуникационная политика президента Венесуэлы - Уго Чавеса. М.: 2007. - С. 35- 36.
} 


\section{Внешнее управление}

Таблица №4

\section{Освещение фигуры Лулы в центральных российских СМИ}

\begin{tabular}{|c|c|c|c|c|}
\hline Источник & Цитата & Оценка & Яркость & Влиятельность \\
\hline РБК daily & $\begin{array}{l}\text { «Заключению соглашения предшествовали 18-часовые пе- } \\
\text { реговоры иранского президента Махмуда Ахмадинежада, } \\
\text { турецкого премьера Тайипа Эрдогана и бразильского пре- } \\
\text { зидента Инасиу Лула да Силва»9 }\end{array}$ & 10 & 5 & 10 \\
\hline Коммерсантъ & $\begin{array}{l}\text { «Я оптимист. Нет людей абсолютно хороших или абсолют- } \\
\text { но плохих. У Ахмади-Нежада наверняка тоже есть очень } \\
\text { хорошая человеческая сторона. А если мы не придем к со- } \\
\text { глашению, я все же буду доволен, что я принял участие в } \\
\text { этих усилиях. Я старался внести свою лепту, и я сделал все, } \\
\text { что мог.. Дмитрий Медведев ответил коротко: - С учетом } \\
\text { того, что мой друг президент Лула - оптимист, я тоже буду } \\
\text { оптимистом. Даю } 30 \%{ }^{10}\end{array}$ & 10 & 10 & 10 \\
\hline Коммерсантъ & $\begin{array}{l}\text { «Бразилия и ее лидер могут стать удобными партнерами } \\
\text { не только для России в целом, но и конкретно для прези- } \\
\text { дента Медведева» } 11\end{array}$ & 10 & 4 & 10 \\
\hline Коммерсантъ & $\begin{array}{l}\text { «может сложиться ситуация, схожая с российской: ушедший } \\
\text { официально в отставку президент Инасиу Лула да Силва } \\
\text { может сохранить власть, в то время как самостоятельность } \\
\text { Руссефф на посту президента будет ограничена.» }{ }^{12}\end{array}$ & 9 & 7 & 10 \\
\hline КоммерсантЪ & $\begin{array}{l}\text { «Был продавцом фруктов, чистильщиком обуви, курьером } \\
\text { в химчистке, с } 14 \text { лет работал на металлургическом заводе } \\
\text { Villares» }^{13}\end{array}$ & 10 & 7 & 10 \\
\hline Эксперт & 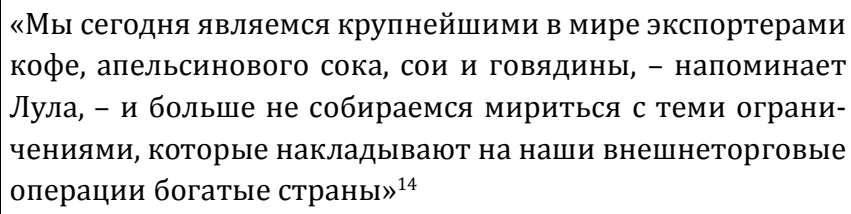 & 10 & 10 & 9 \\
\hline Аргументы и факты & $\begin{array}{l}\text { «Право первого выступления выпало президенту Брази- } \\
\text { лии Луису Инасио Лула да Силва. С его точки зрения, три } \\
\text { главных опасности сегодня... выступил в качестве «заво- }^{\text {дилы» }}{ }^{15}\end{array}$ & 10 & 9 & 8 \\
\hline
\end{tabular}

\footnotetext{
${ }^{9}$ Иран пристроил свой уран [Электронный ресурc]. URL: http://www.rbcdaily.ru/2010/05/18/focus/478748 (30.04.2011).

${ }^{10}$ Президенты перешли от общего к важному. // КоммерсантЪ [Электронный pecypc]. URL: http://www.kommersant.ru/doc/ 1369812? isSearch=True $(30.04 .2011)$.

${ }^{11}$ Россия крепит межбуквенные связи // КоммерсантЪ [Электронный ресурс]. URL: http://www.kommersant.ru/doc/ 1368232? isSearch=True $(30.04 .2011)$.

${ }^{12}$ Бразилия стала тандемократией по - нашему // Коммерсантъ [Электронный pecypc]. URL: http://www.kommersant.ru/ doc/1528262? isSearch=True (30.04.2011).

${ }^{13}$ Южная Америка // КоммерсантЪ [Электронный ресурc]. URL: http://www.kommersant.ru/doc/407793? isSearch=True (30.04.2011).

${ }^{14}$ За тростник ответишь // Эксперт [Электронный ресурc]. URL: http://expert.ru/kazakhstan/2008/18/trosnik/ (30.04.2011).

${ }^{15}$ Штаты возглавят борьбу с самими собой // Аргументы и факты [Электронный pecypc]. URL: http://www.aif.ru/politic/ article/29687 (30.04.2011).
} 


\section{Тренды и управление 2(6) • 2014}

\begin{tabular}{|c|l|c|c|c|}
\hline \multicolumn{1}{|c|}{ Источник } & \multicolumn{1}{|c|}{ Цитата } & Оценка & Яркость & Влиятельность \\
\hline Аргументы и факты & $\begin{array}{l}\text { «Принятие резолюции представляет собой эпизод, ослаб- } \\
\text { ляющй Совбез ООН. Те, кто поддержал новые санкции, по- } \\
\text { казали, что на самом деле не хотели вести переговоры», } \\
\text { заявил президент Бразилии Луис Инасиу Лула да Силва» }\end{array}$ & 6 & 7 & 8 \\
\hline & $\begin{array}{l}\text { «Президент Бразилии Луис Инасиу Лула да Силва заявил } \\
\text { о намерении предоставить Мохаммади-Аштиани убежище. } \\
\text { Сейчас ее дело находится на пересмотре в Верховном суде } \\
\text { Ирана» }\end{array}$ & 7 & 3 & 10 \\
\hline Валовой индекс & & $\mathbf{9 2}$ & $\mathbf{6 9}$ & $\mathbf{9 5}$ \\
\hline
\end{tabular}

Исходя из таблицы можно сделать вывод, что российские влиятельные СМИ в целом оценивают политику Лулы положительно, формируя тем самым у целевой аудитории положительное отношение. Объединение Бразилии с Россией носит экономический, а так же политический характер. Данный вывод сделан на основе Совместного заявления лидеров стран БРИК 16 июня 2009 года ${ }^{18}$.

Согласно проведенным исследованиям становится очевидным интерес международных СМИ к политической деятельности Лула да Силва, однако политика его получила неоднозначную оценку в СМИ США и России.
Данный факт связан с тем, что политика бразильского лидера вызывала определенные трения во внешней политике США и соответствующее была отображена в различных статьях СМИ США, а оценка российских СМИ положительна, т.к. обе страны являются партнерами по группе БРИКС, а также партнерскими отношениями на высшем государственном уровне между президентом России и президентом Бразилии. Факт яркости освещения СМИ политики и персоны Президента Бразилии говорит об успешной имиджевой политики.

Таблища №5

Суммарный показатель оценки СМИ политики Лулы

\begin{tabular}{|c|c|c|c|}
\hline Источник & Оценка & Яркость & Влиятельность \\
\hline Валовой индекс СМИ США & 33 & 82 & 95 \\
\hline Валовой индекс СМИ России & 92 & 69 & $\mathbf{1 9 5}$ \\
\hline Суммарный валовой индекс & $\mathbf{1 2 5}$ & $\mathbf{1 5 1}$ \\
\hline
\end{tabular}

\footnotetext{
${ }^{16}$ Накануне в Нью-Йорке Совет Безопасности ООН вынес решение о новых санкциях против Ирана // Аргументы и факты [Электронный ресурc]. URL: http://www.aif.ru/ politic/article/35395 (30.04.2011).

${ }^{17}$ Сын осужденной на смерть иранки потребовал смягчения приговора матери // РИА Новости [Электронный pecypc]. URL: http://www.rian.ru/world/20110101/316429154. html (30.04.2011).

${ }^{18}$ Совместное заявление лидеров стран БРИК 16 июня 2009 года// Президент России [Электронный ресурс]. URL: http://news.kremlin.ru/ref_notes/209 (17.04.2011).
} 


\section{Внешнее управление}

\section{Библиография}

1. Dreaming with BRICs. The Path to 2050. Global economics paper N 99 [Электронный pecypc]. URL: http.// www.gs.com/inglish/research/reports/report6.html (17.03.2011)

2. Balanзo de Polнtica Externa 2003/2010. [Электронный pecypc]. URL: http://www.itamaraty.gov.br/temas/ balanco-de-politica-externa-2003-2010 (29.04.2011)

3. Мартынов Б.Ф., Константинова Н.С., Проценко А.Е. Имидж России и его восприятие в Бразилии.-М.: ИЛА РАН, 2009.-С.80.

4. O Estado de Sao Paulo, 16.07.2006

5. O Globo, 18.07.2006

6. Совместное заявление лидеров стран БРИК 16 июня 2009 года// Президент России [Электронный pecypc]. URL: http://news.kremlin.ru/ref_notes/209 (17.04.2011)

7. Совместное заявление лидеров стран БРИК 16 июня 2009 года// Президент России [Электронный pecypc]. URL: http://news.kremlin.ru/ref_notes/209 (17.04.2011)

8. Хриптулова О.И. Коммуникационная политика президента Венесуэлы - Уго Чавеса. М.: 2007. - С. 35-36.

9. Иран пристроил свой уран[Электронный ресурc]. URL: http://www.rbcdaily.ru/2010/05/18/focus/478748 (30.04.2011)

10. Президенты перешли от общего к важному. // Коммерсантъ [Электронный ресурc]. URL: http://www. kommersant.ru/doc/1369812?isSearch=True (30.04.2011)

11. Россия крепит межбуквенные связи // КоммерсантЪ [Электронный ресуpc]. URL: http://www. kommersant.ru/doc/1368232?isSearch=True (30.04.2011)

12. Бразилия стала тандемократией по - нашему // Коммерсантъ [Электронный pecypc]. URL: http:// www.kommersant.ru/doc/1528262?isSearch=True (30.04.2011)

13. За тростник ответишь // Эксперт [Электронный ресурc]. URL: http://expert.ru/kazakhstan/2008/18/ trosnik/ (30.04.2011)

14. Штаты возглавят борьбу с самими собой // Аргументы и факты [Электронный pecypc]. URL: http:// www.aif.ru/politic/article/29687 (30.04.2011)

15. Южная Америка // Коммерсантъ [Электронный ресурс]. URL: http://www.kommersant.ru/doc/ 407793?isSearch=True (30.04.2011)

16. Накануне в Нью-Йорке Совет Безопасности ООН вынес решение о новых санкциях против Ирана // Аргументы и факты [Электронный ресурc]. URL: http://www.aif.ru/politic/article/35395 (30.04.2011)

17. Сын осужденной на смерть иранки потребовал смягчения приговора матери // РИА Новости [Электронный pecypc]. URL: http://www.rian.ru/world/20110101/316429154.html (30.04.2011)

18. Манойло А.В. Модель информационно-психологической операции в международных конфликтах. // Право и политика.-2008.-№6. - С.1387-1394.

19. Федякин А.В. Региональные образы как слагаемые образа нации: теоретические и практические задачи для государства и гражданского общества // Вестник Российской нации. 2009. № 6. С. 62-82.

20. Манойло А.В. Специфика цветных революций «Арабской весны». // Известия Уральск. Федерального Ун-та. Сер. 3. Общественные науки. 2013. №3. С. 30-36.

21. Федякин А.В. Становление и эволюция организационного механизма политики формирования позитивного образа Российского государства // Вестник Российской нации. 2010. № 1-2. С. 98-127.

22. Коваленко В.И., Федякин А.В. Проблемы федерализма в трудах мыслителей русского зарубежья. Ч. 1. // Вестник Московского университета. Серия 12. Политические науки. 2011. № 5. С. 61-76.

23. Манойло А.В. Управление конфликтами. Модель психологической операции. // Акмеология.-2009.№1. - С. 64-74.

24. Манойло А.В. «Финиковые революции»: стихия или управляемый хаос?//Международная жизнь. - 2011.-№5. - С. 63-78. 


\section{Тренды и управление 2(6) • 2014}

25. Федякин А.В. Становление и развитие отечественных исследований регионального уровня российской политики: концептуально-теоретические истоки и идейные основания // Вестник Российской нации. 2013. № 3-4. С. 85-106.

26. Манойло А.В. Технологии управления международными конфликтами на примере революций на Ближнем Востоке и в Северной Африке. // Вестник российской нации. - 2011.-№3.

27. Манойло А.В. Национально-государственные модели психологического управления конфликтами. // Обозреватель-Observer.-2008.-№2. - С.118-123.

28. М.Н. Федорец Размышления о становлении федерализма в современной России // Право и политика. - 2012. - 11. - С. 1806 - 1815.

29. Хабриева Т.Я., Лафитский В.И. Комментарии к проекту заключения Венецианской комиссии «О соответствии конституционным принципам решения Верховного Совета Автономной Республики Крым в Украине по организации референдума по вопросу вхождения в качестве субъекта в Российскую Федерацию или восстановления Конституции Крыма 1992 г.» // Журнал зарубежного законодательства и сравнительного правоведения. - 2014. - 1. - С. 129 - 135.

\section{References}

1. Dreaming with BRICs. The Path to 2050. Global economics paper N 99 [Elektronnyi resurs]. URL: http.// www.gs.com/inglish/research/reports/report6.html (17.03.2011)

2. Balanзo de Polmtica Externa 2003/2010. [Elektronnyi resurs]. URL: http://www.itamaraty.gov.br/temas/ balanco-de-politica-externa-2003-2010 (29.04.2011)

3. Martynov B.F., Konstantinova N.S., Protsenko A.E. Imidzh Rossii i ego vospriyatie v Brazilii.-M.: ILA RAN, 2009.-S.80.

4. O Estado de Sao Paulo, 16.07.2006

5. O Globo, 18.07.2006

6. Sovmestnoe zayavlenie liderov stran BRIK 16 iyunya 2009 goda// Prezident Rossii [Elektronnyi resurs]. URL: http://news.kremlin.ru/ref_notes/209 (17.04.2011)

7. Sovmestnoe zayavlenie liderov stran BRIK 16 iyunya 2009 goda// Prezident Rossii [Elektronnyi resurs]. URL: http://news.kremlin.ru/ref_notes/209 (17.04.2011)

8. Khriptulova O.I. Kommunikatsionnaya politika prezidenta Venesuely - Ugo Chavesa. M.: 2007. - S. 35-36.

9. Iran pristroil svoi uran[Elektronnyi resurs]. URL: http://www.rbcdaily.ru/2010/05/18/focus/478748 (30.04.2011)

10. Prezidenty pereshli ot obshchego k vazhnomu. // Kommersant"'”' [Elektronnyi resurs]. URL: http://www. kommersant.ru/doc/1369812?isSearch=True (30.04.2011)

11. Rossiya krepit mezhbukvennye svyazi // Kommersant"'”' [Elektronnyi resurs]. URL: http://www.kommersant.ru/doc/1368232?isSearch=True (30.04.2011)

12. Braziliya stala tandemokratiei po - nashemu // Kommersant"'” [Elektronnyi resurs]. URL: http://www. kommersant.ru/doc/1528262?isSearch=True (30.04.2011)

13. Za trostnik otvetish' //Ekspert [Elektronnyi resurs]. URL: http://expert.ru/kazakhstan/2008/18/trosnik/ (30.04.2011)

14. Shtaty vozglavyat bor'bu s samimi soboi // Argumenty i fakty [Elektronnyi resurs]. URL: http://www.aif. ru/politic/article/29687 (30.04.2011)

15. Yuzhnaya Amerika // Kommersant'"' [Elektronnyi resurs]. URL: http://www.kommersant.ru/doc/ 407793?isSearch=True (30.04.2011)

16. Nakanune v N'yu-Iorke Sovet Bezopasnosti OON vynes reshenie o novykh sanktsiyakh protiv Irana // Argumenty i fakty [Elektronnyi resurs]. URL: http://www.aif.ru/politic/article/35395 (30.04.2011)

17. Syn osuzhdennoi na smert' iranki potreboval smyagcheniya prigovora materi // RIA Novosti [Elektronnyi resurs]. URL: http://www.rian.ru/world/20110101/316429154.html (30.04.2011)

18. Manoilo A.V. Model' informatsionno-psikhologicheskoi operatsii v mezhdunarodnykh konfliktakh. // Pravo i politika.-2008.-№6. - S.1387-1394. 


\section{Внешнее управление}

19. Fedyakin A.V. Regional'nye obrazy kak slagaemye obraza natsii: teoreticheskie i prakticheskie zadachi dlya gosudarstva i grazhdanskogo obshchestva // Vestnik Rossiiskoi natsii. 2009. № 6. S. 62-82.

20. Manoilo A.V. Spetsifika tsvetnykh revolyutsii «Arabskoi vesny». // Izvestiya Ural'sk. Federal'nogo Un-ta. Ser. 3. Obshchestvennye nauki. 2013. №3. S. 30-36.

21. Fedyakin A.V. Stanovlenie i evolyutsiya organizatsionnogo mekhanizma politiki formirovaniya pozitivnogo obraza Rossiiskogo gosudarstva // Vestnik Rossiiskoi natsii. 2010. № 1-2. S. 98-127.

22. Kovalenko V.I., Fedyakin A.V. Problemy federalizma v trudakh myslitelei russkogo zarubezh'ya. Ch. 1. // Vestnik Moskovskogo universiteta. Seriya 12. Politicheskie nauki. 2011. № 5. S. 61-76.

23. Manoilo A.V. Upravlenie konfliktami. Model' psikhologicheskoi operatsii. // Akmeologiya.-2009.-№1. S. 64-74.

24. Manoilo A.V. «Finikovye revolyutsii»: stikhiya ili upravlyaemyi khaos?//Mezhdunarodnaya zhizn'. - 2011.№5. - S. 63-78.

25. Fedyakin A.V. Stanovlenie i razvitie otechestvennykh issledovanii regional'nogo urovnya rossiiskoi politiki: kontseptual'no-teoreticheskie istoki i ideinye osnovaniya // Vestnik Rossiiskoi natsii. 2013. № 3-4. S. 85-106.

26. Manoilo A.V. Tekhnologii upravleniya mezhdunarodnymi konfliktami na primere revolyutsii na Blizhnem Vostoke i v Severnoi Afrike. // Vestnik rossiiskoi natsii. - 2011.-№3.

27. Manoilo A.V. Natsional'no-gosudarstvennye modeli psikhologicheskogo upravleniya konfliktami. // Obozrevatel'-Observer.-2008.-№2. - S.118-123.

28. M.N. Fedorets Razmyshleniya o stanovlenii federalizma v sovremennoi Rossii // Pravo i politika. - 2012. - 11. - C. 1806 - 1815.

29. Khabrieva T.Ya., Lafitskii V.I. Kommentarii k proektu zaklyucheniya Venetsianskoi komissii «0 sootvetstvii konstitutsionnym printsipam resheniya Verkhovnogo Soveta Avtonomnoi Respubliki Krym v Ukraine po organizatsii referenduma po voprosu vkhozhdeniya v kachestve sub"ekta v Rossiiskuyu Federatsiyu ili vosstanovleniya Konstitutsii Kryma 1992 g.» // Zhurnal zarubezhnogo zakonodatel'stva i sravnitel'nogo pravovedeniya. - 2014. - 1. - C. 129 - 135. 